\title{
Trabalho e saúde no cotidiano de enfermagem em um serviço público de pronto-socorro
}

WORK AND HEALTH IN THE NURSING DAY-TO-DAY ROUTINE IN A PUBLIC EMERGENCY SERVICE TRABAJOY SALUD EN EL COTIDIANO DE ENFERMERÍA EN UN SERVICIO PUBLICO DE EMERGÊNCIA

\author{
Daiane Dal Pai ${ }^{1}$, Liana Lautert ${ }^{2}$
}
* Nota prévia de Dissertação de Mestrado vinculada ao Programa de Pós Graduação em Enfermagem da Escola de Enfermagem da Universidade Federal do Rio Grande do Sul - PPGENF/UFRGS.
1 Enfermeira.
Mestranda do PPGENF/UFRGS, bolsista CAPES. daiadalpa@yahoo.com.br
2 Orientadora da Pesquisa. Doutora adjunta ao PPGENF/ UFRGS. lila@enf.ufrgs.br

(a) Adota-se o substantivo feminino de acordo com a designação cultural genérica utilizada para esta categoria profissional.

Recebido: 13/10/2005 Aprovado: 16/11/2005

A violência urbana, os acidentes de trânsito e a precariedade da atenção básica têm sido problemas de forte impacto para a sociedade brasileira na atualidade. Os serviços públicos de emergência são os locais onde estes fenômenos têm prescrito uma realidade de superlotação, ritmo acelerado e sobrecarga de trabalho para os/as profissionais de saúde, relações conflitantes pela tensão da experiência dos usuários e familiares, além da precariedade de recurso humanos e materiais ${ }^{(1-2)}$. Estes aspectos, somados às especificidades dos serviços de emergência - de uma assistência que deve ser realizada de forma imediata, eficiente e integrada - consolidam um cotidiano de trabalho no qual as trabalhadoras ${ }^{\text {(a) }}$ de enfermagem estão inseridas e têm sua saúde constituída, uma vez que o trabalho nunca é neutro em relação à saúde, ou seja, favorece a saúde ou o adoecimento ${ }^{(3)}$.

Com este foco, o presente estudo se inscreve em torno do seguinte problema de pesquisa: que relações o trabalho estabelece com a saúde das profissionais de enfermagem atuantes em um serviço público de emergência da cidade de Porto Alegre-RS? Para atender a essa questão, estão sendo buscados subsídios para a discussão da relação trabalho/ saúde das profissionais de enfermagem atuantes em um serviço público de atendimento externo por meio do conhecimento do contexto organizacional e da dinâmica de trabalho do serviço, bem como das vivências da equipe de enfermagem no trabalho em emergência.

O Serviço de Atendimento Externo do Hospital de Pronto Socorro de Porto Alegre é o local aonde a pesquisa vem sendo realizada, num modelo qualitativo de estudo de caso ${ }^{(4)}$. A mesma encontra-se em fase de coleta de dados, seguindo uma sequiência de análise de documentos da instituição, observação do serviço e entrevista com as profissionais de enfermagem, tendo a Análise de Conteúdo ${ }^{(5)}$ como método de análise dos dados. Para tanto, a presente pesquisa teve sua proposta previamente aprovada pelo Comitê de Ética em Pesquisa da própria instituição.

Os caminhos percorridos permitem divulgar, de forma preliminar, um cotidiano permeado por relações interpessoais que arranjam percursos próprios para a vivência das horas de plantão, ou seja, modos de viver o trabalho que utilizam humor e brincadeiras nos diálogos a fim de amenizar a tensão que se estabelece nos atendimentos de emergência. A organização do trabalho vislumbra o inesperado, assim, a dinâmica de trabalho ora se estabelece para dar conta de ritmos acelerados de trabalho, ora permite uma flexibilidade possível de viver momentos de lazer neste ambiente. Ainda, pode-se inferir que a necessidade de um agir imediato e de uma atuação bem articulada da equipe de saúde faz dos atendimentos de emergência espaços de valorização para os diferentes atores, seus saberes e fazeres. Essa satisfação, relacionada ao heroísmo de salvar vidas, é contrariada pelo sentimento de desamparo vivenciado pelos/as profissionais de enfermagem que se percebem desassistidos na convivência com a desarticulação dos serviços públicos de saúde e recursos materiais muitas vezes escassos.

\section{REFERÊNCIAS}

(1) Deslandes SF. Frágeis deuses: profissionais da emergência entre os danos da violência e a recriação da vida. Rio de Janeiro: FIOCRUZ; 2002.

(2) Skaba MMVF. O vício da adrenalina: etnografia da violência num hospital de emergência. [dissertação] Rio de Janeiro: Escola Nacional de Saúde Pública; 1997.
(3) Dejours C. Normalidade, trabalho e cidadania. Cadernos CRP; 1991.

(4) Stake R. Investigación com estúdios de casos. Madrid: Morata; 1998.

(5) Bardin L. Análise de conteúdo. Lisboa: Edições 70; 1977. 